\section{What to Consider when Making the Buying Decision about a Heat Transfer Fluid for your System - A Report of the Webinar Hosted by Process Heating}

\section{Wright $\mathrm{Cl}^{+}$}

Global Group of Companies, Cold Meece Estate, Cold Meece, Staffordshire, ST15 OSP, UK

\begin{abstract}
This is a report from an educational webinar entitled 'What to consider when making the buying decision about a heat transfer fluid (HTF) for your system' where a panel of experts in the field of heat transfer fluids explained the differences between various heat transfer fluids (e.g., synthetic, glycol and mineral-based HTFs). The session was structured to provide an overview of the 'where, when, how and why' of using HTFs as well as the common application and requirements of HTFs and which HTFs to select for particular process applications. This webinar is available on demand and can be freely accessed by visiting the Process Heating web site.
\end{abstract}

Keywords: Heat transfer fluid; Thermal fluid heat transfer

\section{Abbreviations}

\section{HTF: Heat Transfer Fluid}

\section{Introduction}

This webinar, entitled 'What to consider when making the buying decision about a heat transfer fluid (HTF) for your system', was hosted by Process heating on the $2^{\text {nd }}$ December 2015 [1]. It was led by a panel presentation by six representatives from leading manufacturers of industrial process HTFs. The panel involved: Pete Frentzos, Vice President of Business Development at Radco Industries Incorporation; Conrad Gamble, Senior Engineering Associate at Eastman Chemical Company; L.W. "Budd" Lee, Senior Technical Service Engineer at Dow Industrial Solutions; Ryan Ritz, Global Business Development Manager at Paratherm Heat Transfer Fluids; Mark Smith, General Manager at MultiTherm; and, G.L. "Bud” Warren, Technical Manager at Coastal Chemical Company. Other companies contributed to this content, but did not present at this event. A summary of the presentations and the key points is covered in more detail below.

Talk 1: 'Overview of Heat Transfer Fluids' by L.W.

\section{"Budd" Lee}

Budd explained that the sole purpose of a HTF is to transmit heat from one location to another [2] and that this can be done using a gas or liquid (or steam and water) $[3,4]$ and allows heating as well as cooling. HTFs are used because they have a lower pressure than steam. For example, steam has a vapour pressure of $2,000 \mathrm{psi}(13,790 \mathrm{kPa})$ at $650^{\circ} \mathrm{F}$ $\left(343^{\circ} \mathrm{C}\right)$ whereas a synthetic HTF like Therminol 66 or Globatherm ${ }^{\circledR}$ Syntec [5] would have a vapour pressure between 10.3 and 12.5 psi (between $\sim 71$ and $86 \mathrm{kPa}$ ) at the same temperature. Other reasons are that a HTF has a lower freezing point than water (i.e., $-18.4^{\circ} \mathrm{F}\left[-28^{\circ} \mathrm{C}\right]$ versus $32^{\circ} \mathrm{F}\left[0^{\circ} \mathrm{C}\right]$; Globaltherm ${ }^{\circledR}$ Syntec versus water). HTFs are also less reactive and corrosive than water. Bud then went on to outline the common areas for usage as well as the different types of HTFs with a focus on glycol-water blends, organic and synthetic organic HTFs.

Talk 2: 'Glycol Heat Transfer Fluids' by G.L. "Bud” Warren and L.W. "Budd" Lee

The inhibited glycols that were discussed fell into two categories: hazardous (e.g., ethylene glycol based); and, non-hazardous (e.g., propylene and triethylene glycols). Industrial applications for these HTFs are varied and include: oil and gas processing, the manufacture of plastics and even food processing. It was explained that glycol HTFs are the only HTF that are diluted with water with glycol being added to lower the freeze point and increase the boiling point. The presence of glycol also helps to dissolve the inhibitors that are intermittently added to glycol-based HTFs. Glycol-based HTFs have a number of commercially advantages. Indeed, they are relatively inexpensive, widely available, easy to use and can withstand difficult services. This means they are extremely efficient in terms of their usage and their HTF properties. The presenters provided some clear advice relating to the procurement of glycol-based HTFs with a focus on:

1. Ensuring that inhibitors provide complete protection in all applications.

2. Ensuring that suppliers meet, and are audited, according to international standards for testing, supply, shipping and handling.

3. Ensuring the supplier has a testing facility and service to enable the HTF to be monitored over time.

4. Ensuring additional coolant additives can be supplied as and when needed.

5. Ensuring that a quality control process is operational and that the quality of the product is delivered in the right condition in the right amount of time.

6. Ensure you work with an expert to get the best advice for your HTF system.

${ }^{*}$ Corresponding author: Wright $\mathrm{Cl}$, Global Group of Companies: Cold Meece Estate, Cold Meece, Staffordshire, ST15 0SP, UK, Tel: +44-7967-230-155 E-mail: chrisw@globalgroup.org

Received December 21, 2015; Accepted January 20, 2016; Published January 22,2016

Citation: Wright $\mathrm{Cl}$ (2016) What to Consider when Making the Buying Decision about a Heat Transfer Fluid for your System - A Report of the Webinar Hosted by Process Heating. J Appl Mech Eng 5: 191. doi:10.4172/2168-9873.1000191

Copyright: () 2016 Wright $\mathrm{Cl}$. This is an open-access article distributed under the terms of the Creative Commons Attribution License, which permits unrestricted use, distribution, and reproduction in any medium, provided the original author and source are credited. 


\section{Talk 3: 'Organic Heat Transfer Fluids' by Ryan Ritz}

In describing organic HTFs, Ryan stated "The base chemistry of Organic s(mineral-oil based) HTFs consists of an intricate mixture of petroleum distillates generated during crude oil refining processes." The main constituents are paraffinic hydrocarbons (i.e., alkanes) with traces of naphthenes (cycloalkanes) and some impurities (e.g., aromatics, asphaltenes) for lower grade organic HTFs. Ryan highlighted the potential differences between HTFs and based this on the balance between key product features which included thermal stability, heat transfer efficiency and product purity [6] (Figure 1) and ancillary features (i.e., expansion rate, flash and fire points, resistance to oxidation, start-up temperature and vapour pressure).

It was explained that the operating temperature for a HTF depended on its base chemistry and purity. The example given was that low quality HTFs (i.e., group I base oils) that are less thermally stable and therefore have a higher risk of fouling a HTF system. Group I, II and III base oils were mentioned with group I having the lowest maximal operating temperature $\left(500^{\circ} \mathrm{F} / 260^{\circ} \mathrm{C}\right)$ and group III, stated as being speciality engineered fluids, having the highest $\left(600^{\circ} \mathrm{F} / 316^{\circ} \mathrm{C}\right)$. An interesting aspect was the impact that additive packs had on the functionality and stability of a HTF. Indeed, they potentially have negative effects and work to lower maximal operating temperature and reduce a fluids thermal stability.

Organic HTFs offer a good trade-off between cost, thermal stability and high temperature performance. Such fluids are generally non-toxic, non-hazardous and more user-friendly. However, caution should be exercised where reading this as the buyer/user should always check the material safety data sheet to confirm the hazards and ensure the fluid is handled correctly [7]. This is also true for guidance on shipping. That said organic HTFs are generally easier to ship and dispose of than synthetic/aromatic-based HTFs. When disposing of an organic HTF, there are a few options available which include blending it with spent lube waste or waste fuel.

If a HTF is being used in the processing of food, it was highlighted that a fluid needs to have an NSF HT-1 certification [8], which the supplier should be able to share with the buyer. It is important that this is checked when purchasing a HTF intended for use around food.

In conclusion, it was advised that when selecting a HTF, choose a well-designed, high quality and well-engineered HTF. This is applicable to all fluids. Ryan also stated "Users should be diligent in verifying and comparing heat transfer rates, fouling potential, thermal stability" suggesting that the buyer should know their product before they buy it. Two final comments were provided on colour and viscosity, with colour being a general indicator of HTF condition and possible initial visual indication of the presence of impurities in the HTF. A second general rule was "... avoid fluids with kinematic viscosity $>60 \mathrm{cSt}$ at $40^{\circ} \mathrm{C}$."

\section{Talk 4: 'Synthetic Heat Transfer Fluids' by Pete Frentzos}

This presentation focused on aromatic/synthetic HTFs. Synthetic HTFs being defined as fluids produced by chemical synthesis and specifically chosen for their physical properties - a long-life and efficient performance. Long-life (thermal stability) being was defined as:

1. The resistance to changes in chemical structure over the life time of the HTF.

2. The need to have fewer change-outs (e.g., fewer system flushes and fills).

\section{A lower propensity to foul.}

4. A cleaner operating system.

In the case of efficiency, this was presented in terms of the fluid's performance (i.e., predictable and sustainable) without the need for additional chemicals. The obvious trade-off for synthetic HTFs is the level pf performance versus the cost of the fluid. Irrespective of the HTF, a fluid has lifecycle costs such as the initial cost of filling the system [9], the cost of periodic venting and top-ups over the life of the HTF and then at the end of the fluid's life there will be a cost associated with disposal and refill of the system. The use of a synthetic HTF means it has thermal stability and this would be associated with lower periodic venting and top-ups, both of which would form part of a fluid and system preventive maintenance programme $[10,11]$.

Pete presented some hypothetical examples on the trade-offs between cost and performance that need to be considered when choosing a HTF. The first was a customer wanting a low or high vapour pressure. A high vapour pressure means heating the fluid is very efficient and associated with lower heating costs. A low vapour pressure, however, allows much simpler and potentially cheaper equipment to be used in the system. The second case was a comparison of thermal stability. Comparison of a biphenyl-diphenyl oxide eutectic HTFs (e.g., Dowtherm A, Therminol VP-1 and Globaltherm ${ }^{\circledR}$ Omnitech) are expensive yet they have better thermal stability at higher temperatures than a terphenyl-based HTF (e.g., Therminol 66, Globaltherm ${ }^{\circledR}$ Syntec). Hence, a biphenyl-diphenyl oxide eutectic HTF is expected to have a longer life expectancy when used at higher temperatures for longer periods of time. Another trade-off that needs to be considered is the operating temperature of a HTF as biphenyl-diphenyl oxide-based HTFs have a higher operating temperature and also a higher freezing temperature than terphenyl-based HTFs, which ultimately means they don't go to the lowest temperatures and may not be appropriate for use in colder climates.

Pete concluded "The purchase of a synthetic HTF should be based on value." This clearly means that there needs to be a balance between

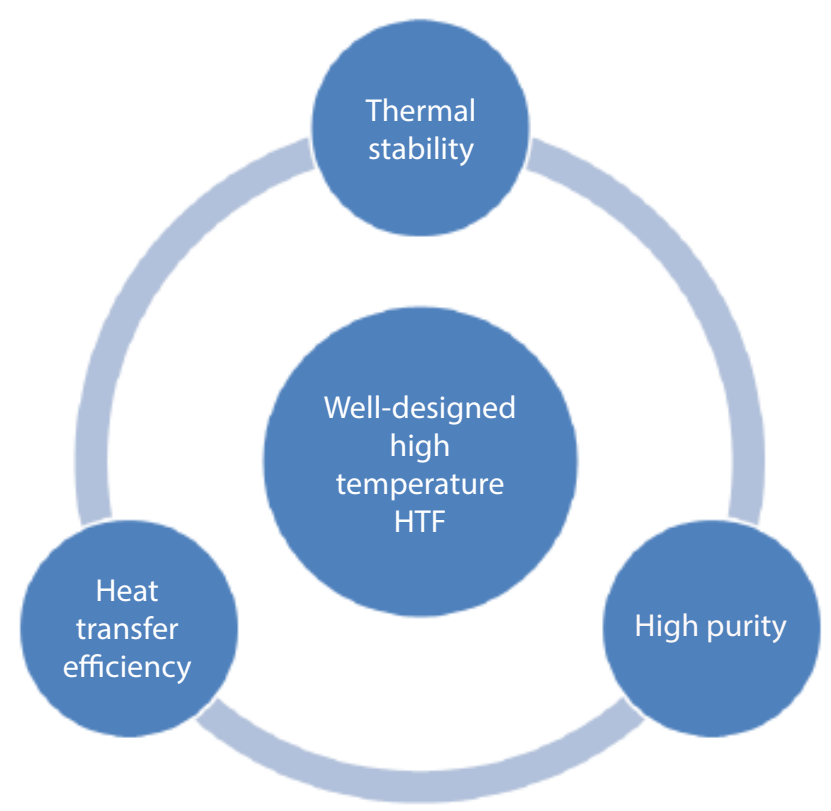

Figure 1: The key product features for a well-designed high temperature HTF. 
performance and cost, and this is influenced by the application where the synthetic HTF is being used. This decision process is not straight forward and assistance from specialist manufacturers of HTFs should be sought.

\section{Conclusion}

These talks were followed by a Q\&A session and can be accessed online by visiting the Process Heating website. Some of the key takehome messages relating to high temperature HTFs are summarised below:

The choice of a HTF should be based on "value" and this is a tradeoff between the cost of the HTF and the performance of the HTF.

The buyer/user should ensure they understand the properties of the HTF as well as the potential trade-offs that may be needed when choosing a HTF and ultimately working with a HTF.

Well-designed, high quality engineered HTFs are readily available from specialty manufacturers at competitive prices, but check the quality control of HTFs and the certification (e.g., NSF HT-1 certification for HTFs being used in food processing).

A well-designed high temperature HTF should be thermally stable, have a high purity and good heat transfer efficiency.

The condition of a HTF needs to be monitored throughout its lifecycle to help sustain an efficient operation and to maintain the health of the HTF as well as the safety of the system [11].

All HTFs will thermally degrade [12] and systems will require periodic venting and top-ups, which forms part of the fluid and system planned preventive maintenance programme.

\section{Acknowledgement}

The author would like to acknowledge the writing support provided by Red Pharm communications, which is part of the Red Pharm company (please see @ RedPharmCo on Twitter).

\section{References}

1. (2015) What to consider when making the buying decision about a heat transfer fluid (HTF) for your system' hosted by Process Heating on $2^{\text {nd }}$ December.

2. Wagner WO (1997) Heat transfer technique with organic media. In Heat transfer media 2(edn) Graefelfing Germany Maria-Eich-Straße: 4-58.

3. Kuser D (2009) Concentrating Solar Power (CSP): Outlook on large potentials and the MENA region. Solar Report.

4. Oetinger J (2011) Troubleshooting heat-transfer fluid systems. Anatomy of a Heat Transfer Fluid Analysis Chemical Engineering.

5. (2015) Global therm high temperature thermal fluid range.

6. Lang C, Lee B (2015) Heat transfer fluid life time analysis of diphenyl oxide/ biphenyl grades for concentrated solar power plants. International conference on concentrating solar power and chemical energy systems, SolarPACES 2014. Energy Procedia 69: 672-680.

7. Wright $\mathrm{Cl}$, Picot E (2016) Safe sampling, handling and storage of bipheny diphenyl oxide heat transfer fluids. International Journal of Materials Chemistry and Physics 2: 9-14.

8. Wright $\mathrm{Cl}$, Bembridge T, Picot E, Premel J (2015) Food processing The use of non-fouling food grade heat transfer fluids. Applied Thermal Engineering 84: 94-103.

9. Wright $\mathrm{Cl}$, Picot E (2015) A case study to demonstrate the value of a system flush and clean prior to filling a plant with virgin heat transfer fluid. Heat Transfer Engineering.

10. Wright $\mathrm{Cl}$, Faure D, Bissemo R (2015) The long-term effectiveness of a lightends removal kit (LERK) in the management of heat transfer fluid plant safety: a case study to show its effectiveness 5 years after installation. Heat Transfer Engineering: 1-18.

11. Ennis $T$ (2009) Safety in design of thermal fluid heat transfer systems Symposium series number 155. Hazards XXI: 162-169.

12. Wright $\mathrm{Cl}$ (2015) Monitoring the degradation of thermal fluids. Turbomachinery 